\title{
A fisiologia como complemento do idealismo kantiano
}

\author{
Physiology as complement of Kant's idealism
}

\author{
Katia Santos*
}

Universidade Federal Rural do Semi-Árido (UFERSA), Pau dos Ferros, RN, Brasil

\section{Resumo}

Este texto discute a importância que Schopenhauer confere à fisiologia, na sua teoria do conhecimento, bem como o parecer do filósofo acerca da unilateralidade do idealismo transcendental de Kant. A partir disso, ressalta a necessidade da mútua complementação das perspectivas objetiva e subjetiva de consideração do intelecto, para a plena compreensão da temática do conhecer. A concepção da formação do conhecimento elaborada por Schopenhauer parte do idealismo kantiano, mas é pensada para resolver questões que estavam abertas no contexto dos debates sobre a coisa em si e sobre a apreensão do dado, subsequentes à publicação de Crítica da razão pura. A fisiologia entra na teoria do conhecimento de Schopenhauer em dois pontos. Em primeiro lugar, por meio das sensações dos sentidos, ela enraíza a realidade do mundo como representação em elementos efetivamente a posteriori, tornando-o algo mais que simples aparência vazia de conteúdo. Em segundo lugar, as considerações fisiológicas acerca do cérebro permitem apontar a origem e a essência do conhecimento da perspectiva objetiva,

*KS: Doutora em Filosofia, e-mail: katia.santos@ufersa.edu.br 
explicando o processo do conhecer por uma via negligenciada por Kant. Em ambos os casos, Schopenhaer entende estar preenchendo lacunas do idealismo kantiano e superando as falhas que afastaram Kant do lado empírico mundo como representação.

Palavras-chave: Schopenhauer. Kant. Teoria do Conhecimento. Idealismo Transcendental. Fisiologia.

\section{Abstract}

This paper discusses the importance that Schopenhauer gives to physiology in his theory of knowledge as well as the philosopher's opinion on the one-sidedness of Kant's transcendental idealism. From this, it emphasizes the necessity of mutual complementation of the objective and subjective perspectives of consideration on the intellect, for the full understanding of the subject of knowing. Schopenhauer's conception of knowledge development starts from Kantian idealism, but is thought to solve questions that were open in the context of the debates about the thing itself and the question of the apprehension of data, subsequent to the publication of Crítica da razão pura. The physiology enters Schopenhauer's theory of knowledge in two ways. In the first place, through the sensations of the senses, it roots the reality of the world as representation in elements effectively a posteriori, making it more than mere empty appearance of content. Secondly, the physiological considerations about the brain allow us to point out the origin and the essence of knowledge from the objective perspective, explaining the process of knowing in a way that was neglected by Kant. In both cases, Schopenhauer understands that he is filling gaps in Kantian idealism and overcoming the flaws that have alienated Kant from the empirical side of the world as representation.

Keywords: Schopenhauer. Kant. Theory of Knowledge. Transcendental Idealism. Physiology.

\section{Introdução}

A teoria do conhecimento schopenhaueriana é uma composição sui generis. Sem dúvida, ela é apoiada no idealismo de Kant, porém, possui ainda outro apoio indispensável, a saber, a constituição fisiológica 
dos sentidos e do corpo animal. Para Schopenhauer, de uma parte, a concepção kantiana acerca da formação do conhecimento é deficiente, na medida em que se ocupa apenas da perspectiva transcendental do mundo como representação, a qual precisa ser complementada com a investigação sobre a origem da intuição empírica. De outra parte, uma compreensão completa do intelecto tem de levar em conta não somente o ponto de vista de suas formas subjetivas, mas também sua perspectiva objetiva, enquanto órgão material no qual se situa o mundo como representação. Para nós, essa feição do pensamento schopenhaueriano não pode ser subestimada, pois é a ela que o filósofo atribui uma das características peculiares de suas ideias. Como se sabe, para Schopenhauer, o aspecto intuitivo do mundo tem primazia sobre o conhecimento abstrato e é sobre ele que toda filosofia deve se debruçar. Reiteradamente, o filósofo ressalta os pontos de contato de seu sistema com relação ao mundo concreto e às ciências empíricas, para evitar que paire acima dos fenômenos e para transpor o abismo entre o metafísico e o físico.

Schopenhauer sempre discorre acerca do idealismo de maneira enfática, evidenciando e ressaltando que o mundo como representação é condicionado pelo sujeito, e que essa é precisamente a sua realidade objetiva. Atribuir a esta última uma existência à parte, não condicionada por nenhum ser cognoscente seria, inclusive, uma contradição. Apesar disso, a existência e a realidade do mundo como representação não são questões que se resolvam apenas com a perspectiva idealista da experiência e do sujeito do conhecer. Schopenhauer acompanhou as críticas que foram feitas a Kant pelos pós-kantianos e assimilou as objeções referentes à apreensão passiva do dado, pelo intelecto, e à dedução da coisa em si. Da pressuposição da coisa em si e da referência a esses elementos externos teriam decorrido as diversas dificuldades que Reinhold, Beck e Maimon, entre outros, tiveram de enfrentar no tocante aos fundamentos do sistema kantiano. Não obstante, o problema tornou-se um quebra-cabeça bastante complexo, pois exigia que a realidade do mundo empírico fosse garantida sem conectá-la à coisa em si, e também sem transformar o conjunto da experiência em aparência sem nenhum sustentáculo.

$\mathrm{Na}$ argumentação schopenhaueriana, os elementos fisiológicos têm tanta importância na construção dos objetos empíricos pelo sujeito 
quanto a constituição a priori do intelecto. De modo semelhante, a compreensão das formas a priori do conhecimeto é tão relevante quanto a da origem e estrutura do cérebro no qual se encontram. Segundo pensamos, ao evidenciar o papel da sensação na edificação dos objetos empíricos e ao iluminar a trajetória da formação material do cérebro, Schopenhauer deixa patente a insuficiência do idealismo transcendental de Kant e, simultaneamente, apresenta uma solução singular à problemática histórica surgida nesse tocante, nas discussões dos pós-kantianos.

\section{Desenvolvimento}

Da perspectiva da construção da experiência, em Crítica da filosofia kantiana, Schopenhauer (2011b, p. 535) afirma que, para distinguir fenômeno e coisa em si, Kant precisou separar rigorosa e detalhadamente o conhecimento a priori do a posteriori. Contudo, enquanto os elementos formais pertencentes ao intelecto teriam sido dissecados minuciosamente, os elementos a posteriori, isto é, o conteúdo empírico da intuição, teria sido tomado como dado. Nesse sentido, Schopenhauer (2011b, p. 550-551, tradução nossa) escreve que,

Depois de considerar conhecimento intuitivo só na matemática, ele negligencia completamente o restante dele, no qual o mundo se apresenta diante de nós, e se fixa somente no conhecimento abstrato, que antes, porém, adquire todo o significado e valor do conhecimento intuitivo, o qual é infinitamente mais significativo, mais geral e de conteúdo mais rico do que a parte abstrata do nosso conhecimento.

A admissão do mundo intuitivo como algo já formado teria sido uma séria falha de Kant, responsável por enredá-lo em contradições insolúveis referentes à dedução da coisa em si. Para Schopenhauer, era imprescindível apontar a origem do conhecimento empírico e descrever o modo como ele se incorpora à consciência, para que a atuação do entendimento na construção da intuição fosse compreendida e distinguida da função própria da razão. No entanto, segundo o filósofo, ao supor a intuição como pronta, Kant teria empregado a lei de causalidade de 
modo impróprio e conectado o intelecto a priori a algo absolutamente externo. Nesse mesmo processo, ele teria admitido a existência da coisa em si, abrindo as portas para diversas críticas e deformações que se fizeram de sua filosofia (SCHOPENHAUER, 2011b, p. 556 et seq.). Esse erro, conforme Schopenhauer, teria sido a razão pela qual Kant não teria compreendido o aspecto essencial de tudo o que se refere à intuição sensível, a saber, seu caráter subjetivo, incluindo aí a sensação dos sentidos.

$\mathrm{Na}$ concepção schopenhaueriana, dizer que um conhecimento é adquirido a priori significa simplesmente que não foi assimilado da experiência ou, o que é o mesmo, não adveio de fora do sujeito. Com efeito, o conhecido a priori pertence originalmente ao intelecto; mais ainda, é a constituição desse intelecto, composta por suas formas próprias (SCHOPENHAUER, 2011b, p. 558-559). O conteúdo das intuições sensíveis, por sua vez, é fornecido pelos sentidos e forma uma parte fundamental de todo o conhecimento, a saber, a fonte a posteriori dele. De acordo com isso, escreve o filósofo, (2011c, cap. 22, p. 322, tradução nossa), "[...] precisamente os sentidos, que em conjunto com as funções $a$ priori do intelecto produzem a intuição, são as fontes mais puras e inocentes de todos os nossos conhecimentos, das quais todo pensamento empresta antes seu conteúdo". Portanto, não é suficiente apenas declarar que se trata de algo dado: é necessário explicarem-se sua natureza, o modo como chega à consciência e como, a partir dele, se institui o mundo real em que vivemos (SCHOPENHAUER, 2011b, p. 559). Kant teria considerado a sensibilidade como uma capacidade de receber impressões externas que, na verdade, já seriam representações, as quais seriam pensadas, depois, com os conceitos puros do entendimento. Todavia, se esse fosse o caso, a intuição não exigiria a ação de nenhuma faculdade intelectual, mas seria algo recebido passivamente e, diz Schopenhauer (2011b, p. 561-562, grifos do autor, tradução nossa),

Daí decorre que o mundo intuitivo estaria lá para nós, mesmo se não tivéssemos nenhum entendimento, que ele entraria de um modo totalmente inexplicável na nossa cabeça, o que ele [Kant] assinala frequentemente com sua afirmação de que a intuição seria dada, sem esclarecer essa indeterminada e figurada expressão. 
Diferentemente, no entender de Schopenhauer, a intuição empírica é a própria realidade, a própria experiência, e exige um processo ativo de construção que depende igualmente do entendimento e das sensações nos sentidos. Ser empírico significa, exatamente, partir das sensações, as quais, ao serem remetidas pelo entendimento à sua causa exterior, constituirão a intuição sensível ou objeto. Para que a sensação deixe de ser meramente subjetiva e se torne representação objetiva, é preciso que seja colocada nas formas do tempo, do espaço e da causalidade. Em suma,

Pois, como os nervos dos órgãos dos sentidos conferem aos objetos que aparecem cor, som, gosto, cheiro, temperatura e assim por diante, também o cérebro confere aos mesmos extensão, forma, impenetrabilidade, mobilidade e assim por diante; numa palavra, tudo o que só é representável por meio do tempo, do espaço e da causalidade (SCHOPENHAUER, 2011c, cap. 2, p. 31, tradução nossa).

Por conseguinte, as formas intelectuais não podem criar o mundo a partir apenas de si mesmas, mas precisam de algo a que se aplicar. Assim, do ponto de vista da construção do mundo empírico pelo sujeito, a teoria do conhecimento schopenhaueriana coloca os sentidos e as sensações nos corpos animais numa posição decisiva. Nesse sentido, a susceptibilidade a influências e mudanças, sentidas como efeitos subjetivos de causas exteriores, é um aspecto fundamental da animalidade. No tocante ao ser humano, Schopenhauer (2012b, p. 353, grifos do autor, tradução nossa) afirma que "A sensibilidade, objetivada nos nervos, é a característica principal do humano e é o verdadeiramente humano no homem". As sensações e os efeitos que os corpos causam entre si são os responsáveis por fornecer o material com o qual o entendimento edificará a experiência. Portanto, a fisiologia dos sentidos e a irritabilidade da substância corporal dos animais aproximam o conhecimento, que surge de um modo totalmente subjetivo, da objetividade concreta da representação. Para nós, a chave da teoria do conhecimento schopenhaueriana, e o que a distingue das dos outros pós-kantianos, é a busca de um fundamento empírico verdadeiramente a posteriori, isto é, algo que não será, no fim das contas, remetido às formas intelectuais subjetivas.

Sobre esse ponto, em Complementos ao mundo como Vontade e representação, Schopenhauer (2011c, cap. 1, p. 20) declara que o único dado realmente 
empírico na intuição sensível é surgimento de uma sensação nos órgãos dos sentidos. A sensação, porém, fornece somente sentimentos subjetivos, localizados e específicos no corpo animal, em nada semelhantes a uma intuição ou a qualquer objeto. "Pois", escreve o filósofo (2012a, § 21, p. 91, tradução nossa), "a sensação, seja qual for sua espécie, é e segue sendo um processo do próprio organismo; como tal, é limitado pela nossa envoltura cutânea e não pode, portanto, conter em si nada que esteja para além daquela envoltura, portanto, fora de nós". Assim, de um lado, as intuições de objetos exigem que os órgãos dos sentidos sejam suscetíveis de influência externa e, de outro, que os materiais fornecidos por eles sejam manipulados pelo entendimento. Consequentemente, a representação remeterá de fato a um substrato empírico, na medida em que se relaciona com sensações, que são elementos incorporados a posteriori no intelecto. Mas nem por isso a intuição sensível será um dado assimilado ou apreendido de fora, já perfeitamente formado. Daí decorre, de uma parte, que as sensações trazem consigo o empírico, mas não os próprios objetos e, de outra parte, que estes últimos não são criações ilusórias de uma mente fechada em si mesma.

A causalidade é a forma intelectual que projeta a causa da sensação no objeto externo. Esse é o processo de construção da realidade empírica, isto é, através do trânsito da impressão sensível à sua causa exterior, realiza-se a intuição do mundo como representação. Nas palavras de Schopenhauer (2011c, cap. 1, p. 20-21, tradução nossa), “Aquela transição da sensação à sua causa que, como mostrei repetidamente, fundamenta toda intuição sensível é suficiente para nos indicar a presença empírica de um objeto empírico no espaço e no tempo, assim, é totalmente suficiente para a vida prática $[. . .]^{\prime \prime}$. Caso não houvesse uma lei de causalidade, conforme o filósofo, as sensações permaneceriam como sentimentos subjetivos, localizados e específicos, sem que jamais pudéssemos alcançar a representação de um mundo objetivo. Em função disso, pode-se dizer que a intuição é intelectual e não apenas sensível, uma vez que a sensação difere completamente dela. Sobre esse ponto, são interessantes as considerações de Cassirer (1993, p. 497, tradução nossa):

Só aqui encontra, segundo Schopenhauer, seu fundamento e sua razão de ser este termo do qual tanto abusa a especulação pós-kantiana. A 
autêntica intuição intelectual não consiste precisamente na capacidade mística de captar o supra-sensível, mas em uma determinada capacidade do intelecto, absolutamente sujeita a leis, que lhe permite plasmar o sensível, captando e interpretando por meio das formas originárias de combinação, que nela mesma se dão, os dados subministrados pelos diferentes sentidos.

Em Da quádrupla raiz do princípio de razão suficiente, Schopenhauer mostra, com uma extensa argumentação e diversos exemplos, que os sentidos não nos apresentam objetos e que a percepção intuitiva do mundo exterior só é realizada pela transição da sensação subjetiva à sua causa objetiva. Ele demonstra, então, que há um grande abismo entre a intuição do mundo exterior e a mera sensação, a qual não passaria de datum para o entendimento ${ }^{1}$. Na interpretação de Cassirer (1993, p. 494, tradução nossa),

O problema, segundo ele [Schopenhauer], não consiste em saber como os juízos da percepção nascem dos juízos da experiência, como as verdades válidas para o indivíduo se convertem em verdades necessárias e de validade geral, mas de recorrer criticamente e de iluminar criticamente, acima de qualquer outra coisa, o caminho que vai da sensação à percepção, do estado subjetivo do "eu" ao objeto percebido e objetivamente intuído.

Para Schopenhauer, os sentidos são prolongações do cérebro, e as sensações que se dão neles são o material da representação intuitiva. O sentido externo seria então a receptividade para impressões advindas de fora, dividindo-se nos cinco sentidos, cada um deles adequado a um dos estados de agregação da matéria. Como ele escreve (2011c, cap. 3, p. 39, tradução nossa), “Assim, o sentido para o rígido (terra) é o tato, para o líquido (água) é o paladar, para o vaporoso, isto é, volátil (neblina, perfume), é o olfato, para o continuamente elástico (ar) é a audição, para o imponderável (fogo, luz) é a visão".

A edificação do mundo pelo entendimento se dá, principalmente, a partir da matéria bruta do tato e da visão, que são os sentidos que fornecem sensações passíveis de serem localizadas no espaço. Os três restantes seriam

1 Cf. § 21 de Da quádrupla raiz do princípio de razão suficiente. 
essencialmente subjetivos, pois suas sensações, embora apontem para uma causa exterior e indiquem a presença de objetos, não possuiriam elementos que determinassem relações espaciais. Com efeito, diz o filósofo, apenas com o sentido do olfato, nunca poderíamos construir uma rosa, do mesmo modo que uma pessoa desprovida de visão poderá ouvir música durante muito tempo, sem que possa ter qualquer representação objetiva dos músicos ou dos instrumentos. Assim, ele continua, a audição se dá apenas na forma do tempo, sendo importante como meio da linguagem e, por isso, é o sentido da razão e da música (2012a, §21, p. 70). O som, no entanto, fica estancado em si mesmo, sem revelar a natureza espacial de sua causa.

Schopenhauer demonstra também, por uma via diferente, que os sentidos não apresentam por si mesmos representações reconhecíveis, prontas para serem assimiladas pelo intelecto. De acordo com ele, embora o tato e a visão apresentem as sensações adequadas à construção dos objetos empíricos, partindo apenas dos dados fornecidos por esses sentidos, não seriam possíveis as representações das três dimensões do espaço, da ação dos corpos uns sobre outros e tampouco das propriedades da extensão, coesão ou figura. O filósofo exemplifica esse ponto argumentando sobre a grande diferença que há entre a sensação de uma corda passando por dentro da mão fechada, no caso de uma pessoa cega, e a intuição do movimento daquele corpo. A partir do atrito sentido e de sua duração, diz ele, essa pessoa construirá um corpo cilíndrico que se move em certa direção, porém, a sensação não oferecerá a representação do movimento. Para isso, isto é, para representar-se a mudança de lugar de um objeto no espaço, em um intervalo de tempo, a sensação do atrito não é suficiente. $\mathrm{O}$ mesmo ocorreria com as representações da causalidade e da materialidade, as quais também demandariam conjuntamente as formas do tempo e do espaço, sendo então completamente distintas de quaisquer sensações.

A importância da fisiologia na teoria do conhecimento schopenhaueriana se mostra também, como dissemos, do ponto de vista objetivo de consideração do intelecto. Dessa perspectiva, as formas do conhecer são a própria constituição fisiológica do intelecto, consubstanciadas no cérebro. Nas palavras de Schopenhauer (2012a, § 21, p. 73, tradução nossa), “[...] A existência dessas formas já prontas e sua precedência em 
relação a toda experiência é o que constitui o intelecto. Fisiologicamente, é uma função do cérebro, o qual a apreende da experiência, tanto quanto o estômago apreende a digestão ou o fígado, a secreção da bílis". Cassirer também sublinha a importância capital do aspecto fisiológico na concepção schopenhaueriana do intelecto. De acordo com esse autor (1993, p. 497, tradução nossa),

O 'mundo' que assim nasce existe somente na representação e para a representação, é, pura e exclusivamente, um produto do cérebro. Nunca se poderá afirmar com a energia necessária, sublinhar-se com força o bastante essa condicionalidade fisiológica. Sem o olho não existiria jamais o mundo das cores: sem o cérebro, jamais existiria o mundo dos corpos no espaço, o mundo das mudanças e das dependências causais no tempo. $\mathrm{O}$ intelecto, que possui como seu patrimônio apriorístico e primitivo todas essas relações e formas, encontra-se absolutamente condicionado por fatores físicos: é função de um órgão material, subordinado portanto a este e que sem ele seria tão impossível como o ato de segurar sem a mão.

Na perspectiva objetiva, Schopenhauer apresenta o intelecto como o ponto máximo a que chegou o desenvolvimento gradual da natureza, no tocante ao conhecimento. A origem do intelecto, nesse ponto de vista, é o aperfeiçoamento da capacidade de satisfação da Vontade, o que se deu por meio do desenvolvimento do cérebro animal. No caso do ser humano, o cérebro se aprimorou até o ponto máximo, possibilitando ir além da intuição sensível e se elevar à razão e aos conceitos (SCHOPENHAUER, 2011a, § 27, p. 213-214). Como o filósofo escreve (2011a, § 27, 215, tradução nossa), “O conhecimento em geral, tanto racional como meramente intuitivo, deriva, então, originalmente da Vontade e pertence à essência dos graus de sua objetivação como simples $\mu \eta \chi \alpha v \eta$, um meio para a conservação do indivíduo e sua espécie, assim como qualquer órgão do corpo". Na condição de parte de um organismo, o cérebro deve ser abordado pelas investigações científicas que explicam sua origem, sua possibilidade, sua necessidade e suas características. Tomado desse modo, ele perde a imponência e dignidade de uma faculdade de conhecimento, para ser considerado da mesma maneira que quaisquer outros órgãos corporais, de quaisquer seres naturais (SCHOPENHAUER, 2011c, cap. 22, p. 318). 
Mais especificamente, o cérebro é a maneira encontrada pela natureza e pela Vontade para satisfazerem-se as necessidades dos animais, mais complexas e variadas do que as dos outros seres vivos. De fato, conforme o filósofo, a criação do cérebro, e com ele do mundo como representação, é um meio para o fim da afirmação da Vontade. Seu aperfeiçoamento como órgão responderia a necessidades crescentes relacionadas à clareza da representação, as quais determinariam que ele fosse cada vez mais desenvolvido. Por meio do cérebro, então, os animais podem buscar sua conservação de modo mais eficaz, utilizando uma capacidade maior de apreensão dos objetos do mundo exterior, de suas circunstâncias e relações (SCHOPENHAUER, 2011c, cap. 22, p. 324-325). Nesse sentido, Schopenhauer (2011c, cap. 22, p. 319, grifos do autor, tradução nossa) explica que

O sistema nervoso, por meio do qual primeiramente o indivíduo animal se torna consciente de si mesmo, é limitado pela sua pele: contudo, elevando-se no cérebro até o intelecto, ele ultrapassa aquela fronteira por meio da forma de conhecer da causalidade, e surge então para ele a intuição como a consciência de outras coisas, como uma imagem de seres no espaço e no tempo, que se modificam em função da lei de causalidade.

O ponto de vista fisiológico de consideração do intelecto esclarece também as formas intelectuais do tempo e do espaço. Devido a sua extrema receptividade, o cérebro realizaria espontaneamente a transição do efeito à causa, produzindo assim a forma do espaço. E, conforme Schopenhauer (2011c, cap. 22, p. 321), o ponto onde o entendimento entrelaça a sensação dos sentidos a sua causa é a fronteira do mundo como Vontade e como representação. Nesse mesmo processo, o cérebro unificaria os cinco sentidos em que se divide a sensibilidade na forma una do sentido interno. Seria algo semelhante ao que Kant chamou de unidade sintética da apercepção, e que seria a condição de possibilidade do autoconhecimento da Vontade. Segundo o filósofo, esse é o foco da atividade cerebral, o próprio sujeito cognoscente (2011c, cap. 22, p. 323).

Essa visão objetiva do intelecto é considerada por Schopenhauer um complemento da abordagem kantiana, na medida em que permitiria 
conhecer externa e geneticamente o mesmo que Kant expôs na perspectiva transcendental. A investigação objetiva, diz Schopenhauer, também leva à conclusão de que o mundo como representação é fenômeno, em função de explicá-lo como um produto fisiológico do cérebro. Com efeito, posto que o mundo intuitivo é formado a partir das leis do intelecto e das sensações dos sentidos, não pode ser a expressão das coisas em si mesmas. Portanto, o que Kant chama de fenômeno seria revelado com a investigação genética e fisiológica do cérebro: o mundo fenomênico seria o produto de um órgão corporal apto a apresentar os objetos no tempo e no espaço, para servirem de motivos para a vontade individual (SCHOPENHAUER, 2011c, cap. 22, p. 333). "Desse modo", escreve Schopenhauer (2011c, cap. 22, p. 334, grifos do autor, tradução nossa),

a visão objetiva do intelecto oferecida aqui, que contém uma gênese do mesmo, torna compreensível que ele, destinado exclusivamente a objetivos práticos, é apenas o meio dos motivos, portanto, cumpre sua função pela correta apresentação destes, e que, se empreendemos construir a coisa em si a partir da complexidade e regularidade da representação que se apresenta objetivamente a nós, o fazemos por nosso próprio risco e responsabilidade.

Na verdade, no entender do filósofo, Kant não teria compreendido que, embora o conhecimento objetivo ofereça apenas aparências, cada indivíduo é também a própria coisa em si, uma vez que se enraíza no mundo. Ainda que não se possa conhecer direta e claramente a essência íntima de nenhum objeto, seria possível esclarecer a ligação do mundo fenomênico com a coisa em si, por meio da apreensão objetiva. Esse é, diz ele (2011c, cap. 22, p. 338), o caminho que lhe possibilitou ir mais longe do que Kant e superar os limites postos por este, na medida em que explicou o processo do conhecimento de todos os seus lados. $\mathrm{O}$ caminho fisiológico é, então, o que expõe a origem e a essência do conhecimento por uma trajetória inversa à transcendental, mas que por fim também o desvenda como secundário e destinado apenas à superfície das coisas. “Assim", afirma Schopenhauer (2011c, cap. 22, p. 338, tradução nossa), 
deve-se, com o importante conhecimento fundamental tomado aqui também em consideração, não apenas, como Kant, ir do intelecto ao conhecimento do mundo, mas também, como eu procedi, do mundo tomado como existente ao intelecto. Portanto, em sentido amplo, essa consideração fisiológica é o complemento daquela ideológica, como dizem os franceses, ou, mais corretamente, transcendental.

\section{Considerações finais}

Segundo pensamos, a teoria do conhecimento de Schopenhauer expõe uma característica interessante da sua filosofia como um todo, a saber, uma forte relação com o empírico. O filósofo não se satisfaz com abstrações ou cadeias meramente conceituais de raciocínios, mas exige sempre a conexão das ideias com o mundo como representação. Para ele, ao contrário do que a tradição filosófica sempre pretendeu, a fonte da metafísica é precisamente a experiência, cuja investigação desvendará o enigma do mundo pela decifração dos hieróglifos presentes, concretamente, no próprio mundo. Em consonância com isso, a ética schopenhaueriana não é normativa, mas somente descreve o fenômeno empírico da moral; a estética é a fuga temporária do mundo como representação, com suas dores e ilusões; e as ciências naturais trazem a comprovação empírica da verdade exposta metafisicamente. Para nós, tudo isso revela uma profunda exigência de sentido para a metafísica, que não pode se reduzir, em última instância, a um mundo teórico, mesmo que perfeitamente deduzido de suas premissas abstratas.

Schopenhauer parece ter sido guiado por essa consciência, ao formular o que seria necessário para que a teoria do conhecimento kantiana se mantivesse de pé, depois dos ataques que sofreu, principalmente, de Jacobi e Schulze. A questão girava em torno da dificuldade de se garantir a realidade objetiva de um produto subjetivo, sem se recorrer a um mundo intuitivo dado ou à coisa em si, casos em que teria sido feito um uso ilegítimo das formas intelectuais. Nesse sentido, a argumentação sobre a diferença abissal entre sensação e intuição foi uma jogada de mestre, com a qual Schopenhauer conectou o mundo como representação a elementos verdadeiramente empíricos, sem no entanto torná-lo um mundo 
assimilado já pronto. E ainda mais surpreendente é ter explicado o processo por meio da causalidade, uma forma a priori do intelecto. Por essas razões, entendemos que a fisiologia dos sentidos e as informações fornecidas por eles, na sensação, são elementos determinantes da teoria do conhecimento schopenhaueriana. Sem eles, o mundo como representação perderia toda a sua sustentação e se tornaria, de fato, uma aparência sem nada que aparecesse, um mundo fictício suspenso no ar.

Aquela mesma preocupação transparece, no tocante à consideração do intelecto como cérebro. Para Schopenhauer, o ponto de vista subjetivo é condicionado e relativo tanto quanto o objetivo, e ambos exigem-se mutuamente para uma compreensão completa e correta do processo do conhecer. As formas a priori do entendimento realizam sua função na construção do mundo da experiência, do mesmo modo como qualquer órgão realiza a função para a qual se destina. Nessa perspectiva, o conhecimento é tomado como um fato do mundo empírico que deve ser investigado enquanto tal. Isso significa que sua origem empírica e sua constituição material devem ser explicadas pelas ciências naturais, para que se compreenda o órgão físico que assegura o conhecer como sua função fisiológica. A consideração objetiva do intelecto mostrará, por fim, que o cérebro surgiu tardiamente na natureza, como um órgão extremamente aperfeiçoado e sensível que, como tudo o que nela existe, remonta à essência em si de todas as coisas, isto é, à Vontade. Nessa condição, o cérebro e sua função intelectual são instrumentos elaborados pela Vontade para sua própria afirmação. E, na medida em que a construção do mundo como representação é um meio para esse fim, sem a perspectiva objetiva do intelecto não compreenderíamos uma parte essencial do processo do conhecer.

\section{Referências}

CASSIRER, E. El problema del conocimiento. III. 1. ed., 4. reimpr. Trad. Wenceslao Roces. México: Fondo de Cultura Económica, 1993. 
SCHOPENHAUER, A. Die Welt als Wille und Vorstellung. Gesamtausgabe. Erster Band. Nach den Ausgaben letzter Hand herausgegeben von Ludger Lütkehaus. 5. Auflage. München: DTV, 2011a.

SCHOPENHAUER, A. Die Welt als Wille und Vorstellung. Gesamtausgabe. Anhang - Kritik der kantischen Philosophie. Nach den Ausgaben letzter Hand herausgegeben von Ludger Lütkehaus. 5. Auflage. München: DTV, 2011b.

SCHOPENHAUER, A. Die Welt als Wille und Vorstellung. Gesamtausgabe. Zweiter Band. Nach den Ausgaben letzter Hand herausgegeben von Ludger Lütkehaus. 5. Auflage. München: DTV, 2011c.

SCHOPENHAUER, A. Über die vierfache Wurzel des Satzes vom zureichenden Grunde. Kleinere Schriften. Sämtliche Werke. Band III. Textkritish bearbeitet und herausgegeben von Wolfgang Frhr. von Löhneysen. 10. Auflage. Stuttgart/ Frankfurt am Main: Suhrkamp, 2012a.

SCHOPENHAUER, A. Über den Willen in der Natur. Kleinere Schriften. Sämtliche Werke. Band III. Textkritish bearbeitet und herausgegeben von Wolfgang Frhr. von Löhneysen. 10. Auflage. Stuttgart/Frankfurt am Main: Suhrkamp, 2012b.

Recebido: 19/01/2018

Received: 01/19/2018

Aprovado: 05/02/2018

Approved: 02/05/2018 